\title{
Antimicrobial Siloxane Statistical and Graft Copolymers Substituted with $t$-Butylamine and $t$-Butylammonium Biocidal Functions
}

\author{
Urszula Mizerska $\cdot$ Witold Fortuniak • Julian Chojnowski • \\ Katarzyna Turecka • Agnieszka Konopacka • \\ Władyslaw Werel
}

Received: 15 May 2010/Accepted: 22 May 2010/Published online: 11 June 2010

(C) The Author(s) 2010. This article is published with open access at Springerlink.com

\begin{abstract}
Two kinds of new biocidal siloxane copolymers were synthesized, poly-[3(t-butylamino)propyl]methylsiloxane-co-(3-chloropropyl)methylsiloxane] and poly [dimethylsiloxane-co-(3-mercaptopropyl)methylsiloxane]g-poly-2(t-butylamino)ethyl methacrylate]. Water-soluble derivatives of these copolymers, having charged ammonium groups, were also obtained. The copolymers were tested against two Gram-positive and three Gram-negative bacterial strains. The antibacterial tests for the water-soluble copolymers with charged ammonium groups were performed in aqueous solutions. Both these copolymers were active against the Gram-positive bacterial strains and inactive or moderately active against Gram-negative bacteria. The uncharged, insoluble, $t$-butylamine substituted copolymers were tested using a two-phase water-copolymer system. In this test both copolymers having the uncharged $t$ butylamine functions showed a high biocidal potency against the bacteria studied including those Gram-negative ones.
\end{abstract}

Keywords Antimicrobial polymers - Biocidal polymers Grafted polysiloxane $\cdot$ Chain transfer polymerization . Organosiloxane copolymers $\cdot t$-Butylamine

This paper is dedicated to Professor Charles U. Pittman Jr. in recognition of his significant contributions to the field of materials chemistry.

U. Mizerska $\cdot$ W. Fortuniak $\cdot$ J. Chojnowski $(\bowtie)$

Center of Molecular and Macromolecular Studies, Polish

Academy of Sciences, Sienkiewicza 112, 90-363 Lodz, Poland

e-mail: jchojnow@cbmm.lodz.pl

K. Turecka $\cdot$ A. Konopacka $\cdot$ W. Werel

Department of Pharmaceutical Microbiology, Medical

University of Gdansk, Hallera 107, 80-416 Gdansk, Poland

\section{Introduction}

Polymer biocides with antimicrobial groups chemically bonded to the polymer chain have attracted a great deal of attention as they very effectively kill bacteria and other microbes without releasing toxic low molar mass compounds to the environment. The strong biocidal potency of these polymers is a result of the high local concentration of active groups [1-7]. Salts of organic cations such as quaternary ammonium [8-15], quaternary phosphonium [15-17], $\mathrm{N}$-alkylpyridinium [18-20], $\mathrm{N}$-alkylimidazolium $[21,22]$, guanidynium [23] and organosulphonium [24] are the most commonly employed biocidal functionalites to be attached to polymers. All of these biocidal functions covalently bonded to polymers are positively charged and have a long carbon chain bonded to the nitrogen, phosphorus or sulfur atoms. Their antimicrobial activity is explained by a strong interaction with the negatively charged microbe cell wall and/or cytoplasmic membrane [1-3]. However, the ionic character of these biocidal polymers may be a serious drawback when they are used as biocidal additives to hydrophobic materials, such as silicone elastomers. The compatibility of these hydrophobic materials with charged polymers is poor. Ionic polymers show a tendency to migrate inside hydrophobic materials during the preparation of prevulcanized blends. Moreover, they may compromise some of the useful properties of materials by increasing their surface energy and dielectric constant.

Some time ago poly-2-t-butylaminoethyl methacrylate was found to be a very active antimicrobial polymer [25-27]. This polymer itself has no ionic group nor has it a long carbon chain at nitrogen. A polysiloxane analogue bearing uncharged biocidal functions would be attractive as an additive to silicone elastomers as its compatibility with 
these materials would be higher and its adverse effect on their useful properties would be lower than with a polysiloxane bearing charged groups.

The purpose of the research reported here is the synthesis of two types of siloxane copolymers bearing $t$-butylamine groups. The first (Scheme 2) is the (3-tbutylaminopropyl)methylsiloxane polymer, which also contains a number of (3-chloropropyl)methylsiloxane units as precursors for the amine-substituted units. The second copolymer (Scheme 3 ) is polydimethylsiloxane with grafted short oligo-2(t-butylamino)ethyl methacrylate chains. This copolymer may contain a number of unreacted (3mercaptopropyl)methylsiloxane units, which could be used in further studies to cross-link the copolymer by a tiol-ene addition process. The second copolymer with its methacrylate chains with $t$-butylamine functions was chosen because this chain has been shown to have a great biocidal potency [25-27]. The first copolymer has a quite different structure from the second because it contains $t$-butylamine side groups attached to a polysiloxane chain by trimethylene bridges. Studies of the antibacterial activity of these copolymers and their protonated derivatives may throw some light on the mechanism of the biocidal action of $t$-butylamine substituted polymers. It is not quite clear whether the high biocidal potency of poly-2(t-butylamine)ethyl methacrylate is an inherent property of tertiary butylamine function [25] or a feature of a special structure of the whole polymer [26].

\section{Experimental}

\subsection{Analytical Methods}

${ }^{1} \mathrm{H}$ NMR spectra were performed using a Brucker AC-200 spectrometer. Deuterated methanol was used as solvent. ${ }^{29} \mathrm{Si}$ NMR spectra were recorded with a Bruker AC-500 instrument working at $99.36 \mathrm{MHz}$ in the inverse gated pulse sequence mode with relaxation delay of $5 \mathrm{~s}$, scan number 1,000 , time domain $65.5 \mathrm{~K}$ and $90^{\circ}$ pulse $15.00 \mu \mathrm{s}$. $\mathrm{CDCl}_{3}$ was used as solvent. ${ }^{13} \mathrm{C}$ NMR were recorded with a Bruker AC-200 spectrometer working at $50.34 \mathrm{MHz}$ using the inverse gated pulse sequence mode with relaxation delay of $20 \mathrm{~s}$, scan number 2,000, time domain $32.8 \mathrm{~K}$ and $90^{\circ}$ pulse $7.00 \mu \mathrm{s} . \mathrm{CDCl}_{3}$ was used as solvent.

Gas Chromatography analyses were performed using a Hewlett Packard HP 6890 chromatograph equipped with a thermal conductivity detector and standard Hewlett Packard HP1 capillary column $l=30 \mathrm{~m}, d=0.53 \mathrm{~mm}$ packed with cross-linked polydimethylsiloxane $(0.88 \mu \mathrm{m}$ film thickness). Helium carrier gas was used: flow rate, $5 \mathrm{~mL} / \mathrm{min}$; detector temperature $250{ }^{\circ} \mathrm{C}$; injector temperature $250{ }^{\circ} \mathrm{C}$; column temperature program, $3 \mathrm{~min}$ at $50{ }^{\circ} \mathrm{C}$ (isothermal), $40-240{ }^{\circ} \mathrm{C}$ at $10{ }^{\circ} \mathrm{C} / \mathrm{min}, 10-15 \mathrm{~min}$ (isothermal).

The size exclusion chromatography analysis was performed using an LDC analytical RefractoMonitor instrument with two phenogel columns covering the molar mass range of $10^{2}-10^{5} \mathrm{~g} / \mathrm{mol}$ and a refractive index detector. Toluene was used as eluent and polystyrene as the standard.

\subsection{Chemicals}

2-(t-Butylamino)ethyl methacrylate, Aldrich $97 \%$ was stored over $\mathrm{CaH}_{2}$ and distilled before use; Fluoresceine $O$-methacrylate, Aldrich 97\%; (3-chloropropyl)methyldichlorosilane, ABCR 95\%; (3-mercaptopropyl)trimethoxysilane, ABCR 95\%; (3-mercaptopropyl)methyldimethoxysilane ABCR 95\%; octamethylcyclotetrasiloxane ABCR 97\%; $t$-Butylamine, Aldrich 98\%; ethyl bromide, Fluka 99\%; AIBN Aldrich 98\%. These chemicals were reagent grade and were used without purification. Purity was checked by gas chromatography. $n$-Hexane, Lab-Scan $95 \%$, analytical grade was dried with $\mathrm{MgSO}_{4}$ and distilled from sodium. DMF POCh pure was dried with $\mathrm{MgSO}_{4}$ for 1 day and distilled under reduced pressure. Methanol Chempur pure p.a. and $n$-butanol POCh pure p.a. were used without purification.

\subsection{Synthesis of Polysiloxanes Substituted with 3-t-Butylaminopropyl Groups $\mathbf{3 a}$ and $\mathbf{3 b}$}

Precursor polymer, (3-chloropropyl)methylsiloxane 1a, $M_{n}=6.0 \times 10^{3} \mathrm{~g} / \mathrm{mol}, M_{\mathrm{w}} / M_{n}=2.1$, was synthesized according to a method described elsewhere [28]. Cyclic oligomers were carefully removed from this copolymer by its precipitation from methylene chloride solution with a limited amount of methanol. Polymer 1a (1.04 g, $7.62 \times 10^{-3} \mathrm{~mol}$ of $\mathrm{Cl}$ ) was mixed with $t$-butylamine $(5.55 \mathrm{~g}, 0.076 \mathrm{~mol})$ and dissolved in a mixture of $n$-butanol $(6 \mathrm{~mL})$ and dimethylformamide $(3 \mathrm{~mL})$. The solution was kept at $80{ }^{\circ} \mathrm{C}$ for $250 \mathrm{~h}$. Then solvents and an excess of amine were removed under reduced pressure and the obtained copolymer 2a (1.3 g, 90\% yield) was analyzed by ${ }^{1}$ H NMR spectroscopy. The yield for the conversion of the chloropropyl group into $t$-butylaminopropyl hydrochloride was $76 \%$. ${ }^{1} \mathrm{H}$ NMR (solvent $\mathrm{CD}_{3} \mathrm{OD}$, in ppm): $0.1-0.3$ (b.s. $\mathrm{CH}_{3} \mathrm{Si}$ ); 0.6-0.8 (b.s. $\mathrm{CH}_{2} \mathrm{Si}$ ); $1.3-1.55$ [b.s. $\left(\mathrm{CH}_{3}\right)_{3} \mathrm{C}$ ]; 1.75-2.0 (b.s. $\mathrm{CH}_{2} \mathrm{CH}_{2} \mathrm{CH}_{2}$ ); 2.9-3.05 (b.t. $\mathrm{CH}_{2} \mathrm{~N}$ ); 3.1-3.25 (b.s. $\left.\mathrm{CH}_{2} \mathrm{Cl}\right)$. Copolymer $2 \mathbf{a}\left(1.00 \mathrm{~g}, 7.2 \times 10^{-3}\right.$ $\mathrm{mol} \mathrm{Cl})$ was dissolved in a mixture of methanol $(20 \mathrm{~mL})$ and triethylamine $(10 \mathrm{~mL})$. The solution was stirred at ambient temperature for $24 \mathrm{~h}$. The precipitate of $\mathrm{Et}_{3} \mathrm{~N}-\mathrm{HCl}$ was separated and an excess of $\mathrm{Et}_{3} \mathrm{~N}$ and methanol was distilled off under reduced pressure. Then the copolymer 
was dissolved in a fresh portion of methanol $(20 \mathrm{~mL})$. Then pyridine $(20 \mathrm{~mL})$ was introduced and the solution was stirred for 3 days at ambient temperature after which it was filtered from precipitated pyridine hydrochloride. Methanol and pyridine were distilled off under reduced pressure. The remaining product, copolymer 3a $(0.85 \mathrm{~g}, 98 \%$ yield $)$ was dissolved in $20 \mathrm{~mL}$ of methanol and precipitated in a large volume of water. $\mathrm{An} \mathrm{AgNO}_{3}$ test showed that it did not contain chloride. It was subjected to ${ }^{1} \mathrm{H}$ NMR analysis (solvent $\mathrm{CDCl}_{3}$, in ppm): $0.0-0.25$ (b.s. $\mathrm{CH}_{3} \mathrm{Si}$ ); 0.45-0.75 (b.s. $\mathrm{CH}_{2} \mathrm{Si}$ ); $1.3-1.6$ [b.s. $\left(\mathrm{CH}_{3}\right)_{3} \mathrm{C}$ ]; $1.85-2.15$ (b.s. $\mathrm{CH}_{2} \mathrm{CH}_{2} \mathrm{CH}_{2}$ ); 2.7-2.95 (b.s. $\mathrm{CH}_{2} \mathrm{~N}$ ); 3.2-3.35 (b.s. $\mathrm{CH}_{2} \mathrm{Cl}$ ). Copolymer 3a, in contrast to copolymer $\mathbf{2 a}$, was not soluble in water. In analogous way copolymers $\mathbf{2 b}$ and 3b were synthesized from poly(3-chloropropyl)methylsiloxane $\mathbf{1 b}, M_{n}=4.2 \times 10^{4} \mathrm{~g} / \mathrm{mol}, M_{n} / M_{\mathrm{w}}=2.3$. $2 \mathrm{~b}$ contained $78 \%$ of the amine hydrochloride substituted units, which were converted to free amine substituted units in $\mathbf{3 b}$.

\subsection{Determination of the Chain Transfer Constant to (3-mercaptopropyl)trimethoxysilane in the Radical Polymerization of 2-t-Butylaminoethyl Methacrylate}

In a $100 \mathrm{~mL}$ Schlenk flask purged with argon and immersed in a bath at temperature $60{ }^{\circ} \mathrm{C}, 3$-mercaptopropyltrimethoxysilane $\left(2.00 \mathrm{~g}, 1.02 \times 10^{-2} \mathrm{~mol}\right), 2$ - $(t$-butylamino)ethyl methacrylate $\left(1.88 \mathrm{~g}, 1.014 \times 10^{-2} \mathrm{~mol}\right)$, $n$-hexane $(3.88 \mathrm{~g}), n$-nonane $(0.26 \mathrm{~g})(\mathrm{GC}$ standard $)$ and $2,2^{\prime}$-azobis(2-methylpropionitrile) (AIBN) $\quad(0.0 .072 \mathrm{~g}$, $\left.4.4 \times 10^{-4} \mathrm{~mol}\right)$, were placed. The mixture was stirred with a magnetic stirrer at $60{ }^{\circ} \mathrm{C}$ in an atmosphere of slowly flowing argon. Conversions of the monomer and the transfer agent were monitored by sampling and gas chromatography technique. The chain transfer constant $k_{\mathrm{tr}} / k_{\mathrm{p}}=0.6,\left(k_{\mathrm{tr}}\right.$ and $k_{\mathrm{p}}$ are rate constants of chain transfer and propagation, respectively) was found from the ratio of the chain transfer agent to monomer consumption in the early stage of the polymerization.

\subsection{Synthesis of Oligo-[2(t-butylamino)ethyl methacrylate] Grafted on Polysiloxane 6a and $\mathbf{6 b}$}

(3-Mercaptopropyl)methyldimethoxysilane (20.4 g, 0.113 mol) was slowly introduced to distilled water $(6.5 \mathrm{~g}$, $0.36 \mathrm{~mol})$ and $\mathrm{HCl} 36 \%$ aqueous solution $(0.5 \mathrm{~mL})$ placed in a glass reactor, equipped with a stirrer, dropping funnel and an ice-water bath. Stirring the mixture was continued while it was allowed to attain room temperature. Volatile components were distilled off under reduced pressure. The remaining hydrolysate $\mathbf{4}$ was composed of linear and cyclic oligo(3-mercaptopropyl)methylsiloxanes. This hydrolysate
(5.33 g, $0.040 \mathrm{~mol}$ of $\mathrm{SH}$ ) was mixed with octamethylcyclotetrasiloxane $\left(\mathrm{D}_{4}\right)\left(23.7 \mathrm{~g}, 0.32 \mathrm{~mol}\right.$ of $\mathrm{Me}_{2} \mathrm{SiO}$ units $)$, hexamethyldisiloxane $\left(1.15 \mathrm{~g}, \quad 7.1 \times 10^{-3} \mathrm{~mol}\right)$ and trifluoromethanesulfonic acid $\left(1.70 \times 10^{-3} \mathrm{~mol}\right)$. The mixture was stirred at room temperature for $50 \mathrm{~h}$. This precursor copolymer $\mathbf{5}$ was dissolved in methylene chloride $(20 \mathrm{~mL})$ and the solution was washed several times with water until neutral $\mathrm{pH}$ was attained. The copolymer was precipitated from its methylene chloride solution with a limited amount of methanol to get rid of cyclic oligomers and dried under a reduced pressure. Copolymer 5 (20.1 g, $67 \%$ yield) was obtained and subjected to ${ }^{1} \mathrm{H}$ NMR, ${ }^{29} \mathrm{Si}$ NMR investigation and SEC analysis. ${ }^{1} \mathrm{H}$ NMR (solvent $\mathrm{CDCl}_{3}$, in ppm): $-0.05-1.5$ (b.s. $\mathrm{CH}_{3} \mathrm{Si}$ ); 0.56-0.68 (m. $\mathrm{CH}_{2} \mathrm{Si}$ ); $1.25-1.35$ (t. SH); $1.55-1.69$ (m. $\mathrm{CH}_{2} \mathrm{CH}_{2} \mathrm{CH}_{2}$ ); 2.47-2.57 (q. $\mathrm{CH}_{2} \mathrm{SH}$ ). ${ }^{29} \mathrm{Si} \mathrm{NMR} \mathrm{(solvent} \mathrm{CDCl}_{3}$, in ppm): -23.1-(-23.6) [b.m. $\left.\mathrm{MeSi}\left(\mathrm{CH}_{2}\right)_{3} \mathrm{SH}\right] ;-21.6-(-22.0)$ [b.m. $\mathrm{SiMe}_{2}$ ]; 5.23-5.26 (s. $\left.\mathrm{SiMe}_{3}\right) ; M_{n}$ (from $\left.{ }^{29} \mathrm{Si} \mathrm{NMR}\right)$ $1.44 \times 10^{4} \mathrm{~g} / \mathrm{mol}$ SEC (polystyrene standard): $M_{n}$ $1.3 \times 10^{4} \mathrm{~g} / \mathrm{mol} ; M_{\mathrm{w}} / M_{n}$ 1.85. Average macromolecule contained (by NMR): 18 [3- $\left.\mathrm{HS}\left(\mathrm{CH}_{2}\right)_{3} \mathrm{MeSiO}\right]$ units, 160 $\left[\mathrm{Me}_{2} \mathrm{SiO}\right]$ units and $2 \mathrm{Me}_{3} \mathrm{SiO}_{0.5}$ units.

Copolymer $5\left(1.50 \mathrm{~g}, 1.88 \times 10^{-3} \mathrm{~mol}\right.$ of the SH containing units) was mixed with 2(t-butylamino)ethyl methacrylate $\left(2.76 \mathrm{~g}, 14.9 \times 10^{-3} \mathrm{~mol}\right)$, dried $n$-hexane $(4.3 \mathrm{~mL})$ and AIBN $\left(0.092 \mathrm{~g}, 5.6 \times 10^{-4} \mathrm{~mol}\right)$. The mixture was stirred at $60^{\circ} \mathrm{C}$ for $1.5 \mathrm{~h}$ in an atmosphere of nitrogen. The polymerization was controlled by gas chromatography and performed to about $80 \%$ of monomer conversion. Solvent and remaining monomer were removed by evaporation at reduced pressure $(2 \mathrm{~mm})$. Graft copolymer 6a $(2.50 \mathrm{~g}, 85 \%$ yield) was purified from the 2(t-butylamino)ethyl methacrylate homopolymer by precipitation from its methanol solution with a limited amount of the mixture of methanol with water $1: 1(\mathrm{v} / \mathrm{v})$. The operation was repeated five-times until the ratio of the integration of the $\mathrm{CH}_{3} \mathrm{C} / \mathrm{CH}_{3} \mathrm{Si}$ signals in the ${ }^{1} \mathrm{H}$ NMR spectrum did not change. The copolymer was dried under reduced pressure and analyzed. ${ }^{1} \mathrm{H}$ NMR (solvent $\mathrm{CD}_{3} \mathrm{OD}$, in ppm): $0.04-0.2$ (b.s. $\mathrm{CH}_{3} \mathrm{Si}$ ); $0.6-0.72$ (b.s. $\mathrm{CH}_{2} \mathrm{Si}$ ); $0.9-1.05,1.05-1.2,1.2-1.35$ (b.m. $\mathrm{CH}_{3} \mathrm{CCO}$ ); 1.1-1.25 (b.s. $\mathrm{CH}_{3} \mathrm{CN}$ ); 1.6-1.75 (b.s. $\mathrm{CH}_{2} \mathrm{CH}_{2} \mathrm{CH}_{2}$ ); 1.75-2.2 (b.m. $\mathrm{CH}_{2} \mathrm{C}$ ); 2.5-2.65 (b.m. $\mathrm{CH}_{2} \mathrm{~S}$ ); 2.65-2.75 (CH); 2.75-2.9 (b.m. $\mathrm{CH}_{2} \mathrm{~N}$ ); 4.0-4.25 (b.m. $\mathrm{CH}_{2} \mathrm{O}$ ). ${ }^{13} \mathrm{C}$ NMR (solvent $\begin{array}{llllll}\left.\mathrm{CDCl}_{3}\right): & -0.537 & \left(\mathrm{CH}_{3}\right)_{3} \mathrm{Si} ; & 0.986 & \left(\mathrm{CH}_{3}\right)_{2} \mathrm{Si} ; & 1.730\end{array}$ $\mathrm{CH}_{3} \mathrm{SiCH}_{2} ; 16.963 \mathrm{CH}_{2} \mathrm{Si} ; 28.960\left(\mathrm{CH}_{3}\right)_{3} \mathrm{C} ; 30.882 \mathrm{CH}_{2} \mathrm{~S}$; $40.819 \mathrm{CH}_{2} \mathrm{~N} ; 44.694,45.006 \mathrm{CH}_{2} \mathrm{C} ; 50.167 \mathbf{C N} ; 65.513$ $\mathrm{CH}_{2} \mathrm{O}$. Copolymer 6a had $M_{n}=2.4 \times 10^{4} \mathrm{~g} / \mathrm{mol}$. The average macromolecule contained $160 \mathrm{Me}_{2} \mathrm{SiO}$ units and about seven units with a grafted oligo[2-t-butylaminoethyl] methacrylate chain, which contained about nine methacrylate units on average (together $2.6 \times 10^{-3} \mathrm{~mol} / \mathrm{g}$ $t$-butylamine). 
The polymerization was repeated using $2.00 \mathrm{~g}$ $\left(3.97 \times 10^{-3} \mathrm{~mol}\right.$ of the SH containing units) of copolymer 5, $3.68 \mathrm{~g}\left(19.9 \times 10^{-3} \mathrm{~mol}\right)$ of $2(t$-butylamino $)$ ethyl methacrylate, $0.123 \mathrm{~g}\left(7.5 \times 10^{-4} \mathrm{~mol}\right)$ of AIBN in $7 \mathrm{~mL}$ of $n$-hexane. The mixture was stirred for $12 \mathrm{~h}$ at $60^{\circ} \mathrm{C}$. The polymerization proceeded almost to full monomer conversion. After the removal of solvent, $3.5 \mathrm{~g}$ (78\% yield) of raw grafted copolymer $\mathbf{6 b}$ was isolated and subjected to purification from the methacrylate homopolymer. $6 \mathbf{b}$ had $M_{n}=3.4 \times 10^{4} \mathrm{~g} / \mathrm{mol}$ and contained on average 110 $t$-butylamine substituted units; about six units per graft.

\subsection{Synthesis of Oligo-[2(N,N-t-butylethylammonio) ethyl methacrylate bromide] Grafted on Polysiloxane 7b}

Copolymer $6 \mathbf{b}\left(0.30 \mathrm{~g}, 9.6 \times 10^{-4} \mathrm{~mol} t\right.$-butylamine $)$ was subjected to the Mienschutkin reaction with ethyl bromide $\left(5.84 \mathrm{~g}, 5.4 \times 10^{-2} \mathrm{~mol}\right)$ in DMF $(10 \mathrm{~mL})$. The reaction was carried out at room temperature for 7 days. The solvent and excess of ethyl bromide were evaporated at a reduced pressure. Soluble in water copolymer $\mathbf{7 b}$ was obtained $(0.54 \mathrm{~g})$ having about $90 \%$ of its amine groups converted to ammonium groups as determined from ${ }^{1} \mathrm{H}$ NMR. ${ }^{1} \mathrm{H}$ NMR (solvent $\mathrm{CD}_{3} \mathrm{OD}$, in ppm): 0.05-0.15 (b.s. $\mathrm{CH}_{3} \mathrm{Si}$ ); 0.6-0.7 (b.s. $\mathrm{CH}_{2} \mathrm{Si}$ ); 0.95-1.25 (b.m. $\mathrm{CH}_{3} \mathrm{C}$ ); 1.3-1.4 (b.t. $\left.\mathrm{CH}_{3} \mathrm{CH}_{2} \mathrm{Si}\right) ; 1.45-1.6 \quad$ [b.s. $\left(\mathrm{CH}_{3}\right)_{3} \mathrm{C}$, $\mathrm{CH}_{2} \mathrm{CH}_{2} \mathrm{CH}_{2}$ ]; 2.0-2.3 (b.s. $\mathrm{CH}_{2} \mathrm{C}$ ); 2.5-2.6 (b.s. $\mathrm{CH}_{2} \mathrm{~S}$ ); 3.35-3.5 (b.m. $\mathrm{CH}_{2} \mathrm{~N}$ ); 4.35-4.55(b.s. $\mathrm{CH}_{2} \mathrm{O}$ ).

\subsection{Antibacterial Activity Assessment}

The antibacterial tests for the cationic biocidal copolymers were performed in aqueous solutions using a method similar to that described elsewhere [21]. The minimum inhibitory concentrations (MIC) and the minimum bactericidal concentrations (MBC) were determined for five bacteria strains: Staphylococcus aureus (ATCC 6538), Enterococcus hirae (ATTC 10541), Escherichia coli (ATTC 8739), Proteus vulgaris (NCTC 4635) and Pseudomonas aeruginosa (ATCC 9027). The MIC and MBC determinations were performed in three independent measurements using the standard broth dilution technique [28] with inoculums of approximately $1 \times 10^{5} \mathrm{CFU} \mathrm{mL}^{-1}$. The tested copolymers were dissolved, diluted in geometric progression and dispensed into the wells of a microplate to which an overnight bacterial culture, diluted with MuellerHinton broth to the proper density, was introduced. Microplates were incubated for $24-36 \mathrm{~h}$ at $37{ }^{\circ} \mathrm{C}$. Then the growth of bacteria in the wells was examined to determine the MIC value, which was taken as a lowest concentration of copolymer that inhibits visible growth of bacteria. The MBC value was found by the observation of the ability of the bacteria with inhibited growth to survive after transfer to Mueller-Hinton agar plate. The MBC value was taken as a lowest concentration of copolymer that would kill all visible bacteria.

Another method was used in the antibacterial tests for non-ionic biocidal copolymers, which were insoluble in water. Round flat bottom wells of the diameter of $\Phi=1.2 \mathrm{~cm}$ of polystyrene cell culture multi-dishes were coated with a biocidal copolymer layer of $1 \mathrm{~mm}$ thickness. For this purpose concentrated solutions of these polymers in methanol were placed in wells and the solvent was evaporated. Some wells were additionally washed eighttimes with water and dried. Then the coated multi-dishes were heated in a drying box at $60{ }^{\circ} \mathrm{C}$ for $5 \mathrm{~h}$. A bacterial culture, $400 \mu \mathrm{L}$, with suitable optical density was dispensed to a well. Samples of $20 \mu \mathrm{L}$ of the bacterial suspension were withdrawn in a time interval starting from time zero. They were diluted 10-, 100-, and 1,000-fold. A $100 \mu \mathrm{L}$ of each dilution was transferred to an agar plate and incubated at $37{ }^{\circ} \mathrm{C}$ for $24 \mathrm{~h}$. Colony forming units, $\mathrm{CFU}$, were calculated using Scheme 1.

\section{Results and Discussion}

\subsection{Synthesis of 3-t-Butylaminopropyl Substituted Polysiloxanes}

Poly(3-t-butylaminopropyl)methylsiloxane-co-(3-chloropropyl)methyl-siloxane was obtained by the partial amination of 3-chloropropyl groups in a (3-chloropropyl)methylsiloxane polymer by $t$-butylamine according to Scheme 2.

Precursor polymers 1a and 1b, poly(3-chloropropyl)methylsiloxanes, were synthesized by cationic equilibrium polymerization (equilibration) of the cyclic siloxane polymer products by hydrolytic polycondensation of $\left[3-\mathrm{Cl}\left(\mathrm{CH}_{2}\right)_{3}\right] \mathrm{MeSiCl}_{2}$ in a similar way to that described previously [29]. Hexamethyldisiloxane (MM) was added to limit the molar mass of the copolymer and to terminate the chain by $\mathrm{Me}_{3} \mathrm{Si}$ groups. Volatile cyclic oligomers were removed by the precipitation of the copolymer from methylene chloride solution with a limited amount of methanol. The amination (Menschutkin reaction) was performed by heating a mixture of the precursor copolymer with a large excess of $t$-butylamine in a dimethylformamide (DMF)- $n$-butanol solution. The course of the reaction was monitored by proton NMR. The reaction was stopped when at least $70 \%$ of the chloropropyl groups had reacted. In this way copolymers $\mathbf{2 a}$ and $\mathbf{2 b}$ were obtained whose amine groups were complexed with $\mathrm{HCl}$. They were treated with a large excess of triethylamine and subsequently with pyridine to obtain the free amine 
$\mathrm{CFU} / \mathrm{ml}=($ Number of colonies) $\mathrm{x}$ (Degree of dilution) $/$ Volume of the inoculum on plate

Scheme 1 Calculation of colony forming units, CFU

Scheme 2 Synthesis of poly $\{[(3-t$-butylam-

moniopropyl)methylsiloxane chloride]-co-(3-chloropropyl)methylsiloxane $\}, 2$ and poly[(3-t-butylaminopropyl)methylsiloxane-co-(3-

chloropropyl)methylsiloxane], 3
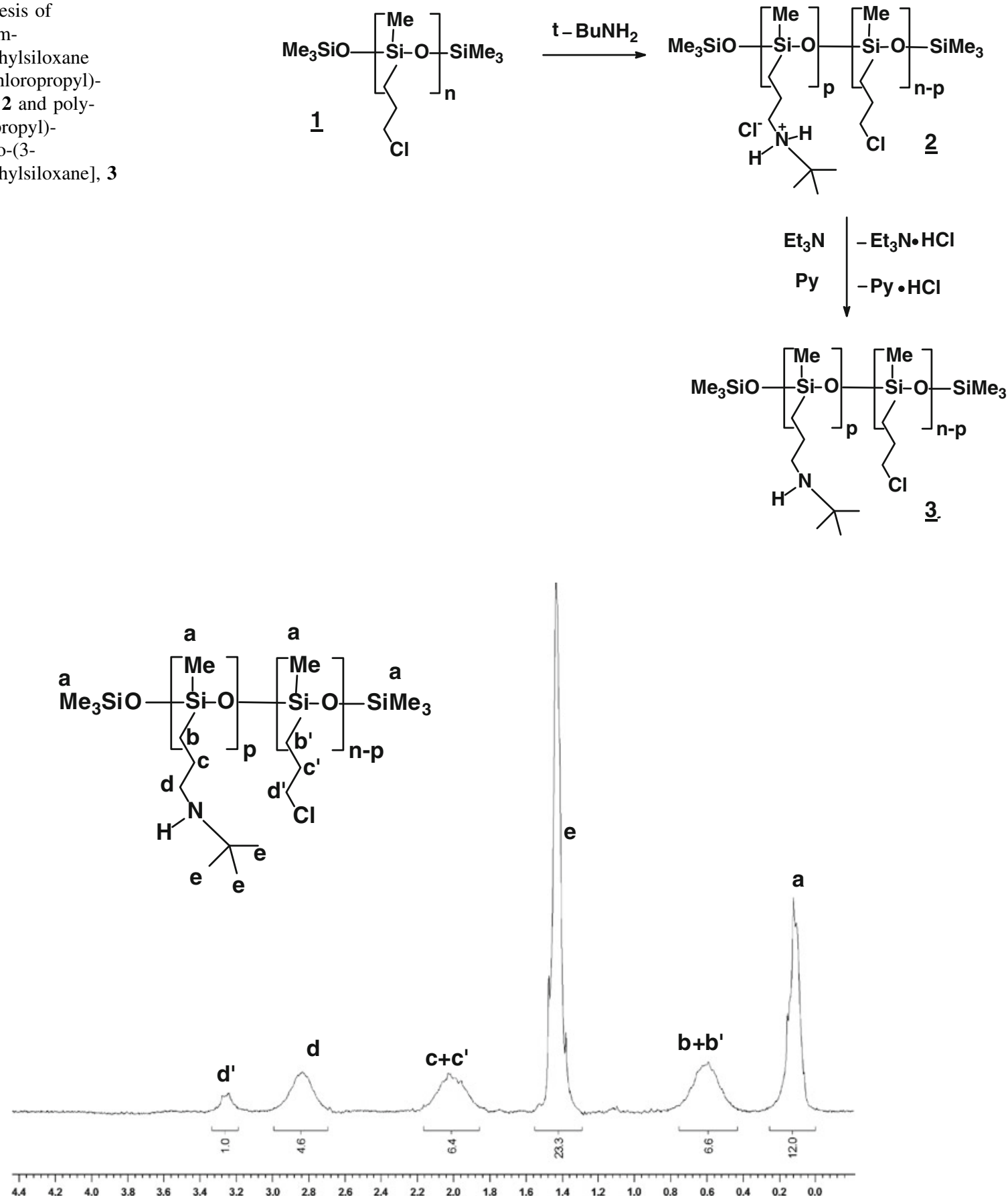

Fig. 1 The ${ }^{1} \mathrm{H}$ NMR spectrum of poly[(3-t-butylaminopropyl)methylsiloxane-co-(3-chloropropyl)methylsiloxane], copolymer 3a

substituted copolymers, 3a and $\mathbf{3 b}$. These were additionally purified by precipitation in water from methanol solution. The ${ }^{1} \mathrm{H}$ NMR spectrum of copolymer $\mathbf{3 a}$ is presented in Fig. 1. The characteristics of copolymers are shown in Tables 1 and 2.

\subsection{Synthesis of $t$-Butylamine Substituted} Oligomethacrylate Grafted on Polysiloxane

Chain transfer polymerization was used for the grafting of polymethacrylate bearing $t$-butylamine in the ester groups 
Table 1 Antibacterial activity of $t$-butylammonium substituted siloxane copolymers studied in aqueous solution

\begin{tabular}{|c|c|c|c|c|c|c|c|}
\hline \multirow[t]{3}{*}{ Polymer no. } & \multirow{3}{*}{$\begin{array}{l}M_{n} \times 10^{-3} \\
\left(\mathrm{~g}^{\prime} \mathrm{mol} M_{\mathrm{w}} / M_{n}\right)\end{array}$} & \multirow{3}{*}{$\begin{array}{l}d \times 10^{3} \\
(\mathrm{~mol} / \mathrm{g})^{\mathrm{a}}\end{array}$} & \multicolumn{5}{|c|}{$\mathrm{MIC} /(\mathrm{MBC})(\mu \mathrm{g} / \mathrm{mL})$} \\
\hline & & & \multicolumn{2}{|c|}{ Gram-positive bacteria } & \multicolumn{3}{|c|}{ Gram-negative bacteria } \\
\hline & & & $\begin{array}{l}\text { Enterococcus } \\
\text { hirae }\end{array}$ & $\begin{array}{l}\text { Staphylococcus } \\
\text { aureus }\end{array}$ & $\begin{array}{l}\text { Escherichia } \\
\text { coli }\end{array}$ & $\begin{array}{l}\text { Proteus } \\
\text { vulgaris }\end{array}$ & $\begin{array}{l}\text { Pseudomonas } \\
\text { aeruginosa }\end{array}$ \\
\hline $2 \mathbf{a}$ & $8.0(2.1)$ & 4.2 & $80(80)$ & $40(40)$ & $300(300)$ & $>10,000$ & $5,000(5,600)$ \\
\hline $2 \mathbf{b}$ & $57(2.3)$ & 4.2 & $40(160)$ & $40(40)$ & $300(300)$ & $>10,000$ & $5,000(5,000)$ \\
\hline $7 b$ & 40 & 2.7 & $40(40)$ & $20(20)$ & $80(80)$ & $>2,500$ & $1,250(1,250)$ \\
\hline $8^{\mathrm{b}}$ & 22 & 3.3 & $<7.5^{\mathrm{b}}$ & $4^{\mathrm{b}}$ & $10^{\mathrm{b}}$ & $80^{\mathrm{b}}$ & $80^{\mathrm{b}}$ \\
\hline
\end{tabular}

${ }^{a}$ Density of biocidal groups in polymer

b Poly $\{[3(N, N, N-n$-octyldimethylammonio)propyl]methylsiloxane chloride $\}$, data from Ref. 21

Table 2 Antibacterial activity of $t$-butylamine substituted siloxane copolymers studied in a water-polymer two phase system

\begin{tabular}{|c|c|c|c|c|c|c|c|}
\hline \multirow[t]{3}{*}{ Polymer no. } & \multirow{3}{*}{$\begin{array}{l}M_{n} \times 10^{-3} \mathrm{~g} / \mathrm{mol} \\
\left(M_{\mathrm{w}} / M_{n}\right)\end{array}$} & \multirow{3}{*}{$\begin{array}{l}d \times 10^{3} \\
(\mathrm{~mol} / \mathrm{g})\end{array}$} & \multicolumn{5}{|c|}{$t\left(\log N_{0} / N=2\right)(\min )$} \\
\hline & & & \multicolumn{2}{|l|}{ Gram-positive } & \multicolumn{3}{|c|}{ Gram-negative } \\
\hline & & & $\begin{array}{l}\text { Enterococcus } \\
\text { hirae }\end{array}$ & $\begin{array}{l}\text { Staphylococcus } \\
\text { aureus }\end{array}$ & $\begin{array}{l}\text { Escherichia } \\
\text { coli }\end{array}$ & $\begin{array}{l}\text { Proteus } \\
\text { vulgaris }\end{array}$ & $\begin{array}{l}\text { Pseudomonas } \\
\text { aeruginosa }\end{array}$ \\
\hline $\mathbf{3 a}$ & $6.8(2.1)$ & 4.5 & 10 & 15 & 15 & $-{ }^{\mathrm{a}}$ & $<5$ \\
\hline 3b & $48(2.3)$ & 4.7 & 5 & $<15$ & 5 & $30^{\mathrm{b}}$ & 1 \\
\hline $\mathbf{6 a}$ & 24 & 2.6 & 90 & 60 & 30 & 90 & 30 \\
\hline $6 \mathbf{b}$ & 34 & 3.3 & 10 & 20 & 15 & 30 & 20 \\
\hline
\end{tabular}

Time needed to attain the reduction of CFU $10^{2}, t\left(\log N_{0} / N=2\right)$

a 50 -fold reduction after $10 \mathrm{~min}$, but later CFU increases

${ }^{b} \mathrm{CFU}$ increases after a long time

on a polysiloxane chain. The synthesis of poly[dimethylsiloxane-co-(3-mercaptopropyl)methylsiloxane]-g-poly(2$t$-butylaminoethyl methacrylate) was performed according to Scheme 3.

The precursor siloxane copolymer $\mathbf{5}$, functionalized with 3-mercaptopropyl groups, was synthesized by cationic equilibrium copolymerization of octamethylcyclotetrasiloxane with the hydrolyzate of (3-mercaptopropyl)methyldiethoxysilane and catalyzed by $\mathrm{CF}_{3} \mathrm{SO}_{3} \mathrm{H}$. Hexamethyldisiloxane was added to control the molar mass of the copolymer product. The copolymer, after the removal of cyclic compounds, was characterized by ${ }^{1} \mathrm{H}$ and ${ }^{29} \mathrm{Si}$ NMR and SEC.

2-(t-butylamino)ethyl methacrylate was subjected to radical polymerization initiated with $2,2^{\prime}$-azobis(2-methylpropionitrile (AIBN) in the presence of the precursor siloxane copolymer 5. 3-Mercaptopropylsilyl groups pendant to the polysiloxane chain were efficient chain transfer agents in this radical polymerization [30]. The chain transfer to this group led to the grafting of the oligomethacrylate chain to polysiloxane through a thioether bridge. We assumed that the chain transfer constant in this system would be similar to that for the chain transfer to 3(mercaptopropyl)trimethoxysilane, which was determined in separate experiment (see Sect. 2). The value of this constant was $k_{\mathrm{tr}} / k_{\mathrm{p}}=0.6$ where $k_{\mathrm{tr}}$ and $k_{\mathrm{p}}$ are chain transfer constant and propagation constant, respectively. This means that the molar ratio of monomer-to-chain transfer agent changes fairly little when the polymerization proceeds. Thus, the reaction may be performed to give high monomer conversion. The methacrylate homopolymer was removed by careful precipitation of the graft copolymer product from its methanol solution by the addition of a limited amount of a water-methanol mixture. This precipitation procedure was repeated until the ratio of intensities of $\mathrm{NCCH}_{3}$ and $\mathrm{SiCH}_{3}$ peaks in the copolymer ${ }^{1} \mathrm{H}$ NMR spectrum did not change after subsequent precipitation. The obtained graft copolymers $\mathbf{6 a}$ and $\mathbf{6 b}$, which were synthesized from the same precursor polysiloxane, differed in the number of $t$-butylamine functions and in the number of grafts. Copolymers $\mathbf{6 a}$ and $\mathbf{6 b}$ were characterized by SEC and ${ }^{1} \mathrm{H}$ NMR (Fig. 2.

This water-insoluble free-amine-substituted copolymer 6b was subjected to alkylation with ethyl bromide to prepare a polysiloxane $\mathbf{7 b}$ that is grafted with oligomethacrylate having [2(N,N-t-butylethylammonio)ethyl bromide] ester groups, which made this copolymer water-soluble. 
Scheme 3 Synthesis of the polysiloxane with grafted oligo2(t-butylamino)ethyl methacrylate chains 6 and the polysiloxane with grafted oligo[2(N,N-tbutylethylammonio)ethyl methacrylate bromide], 7

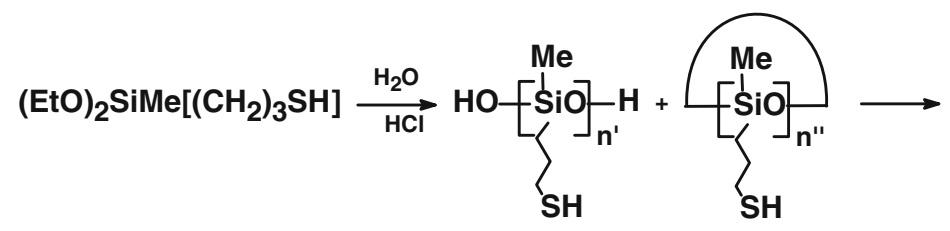

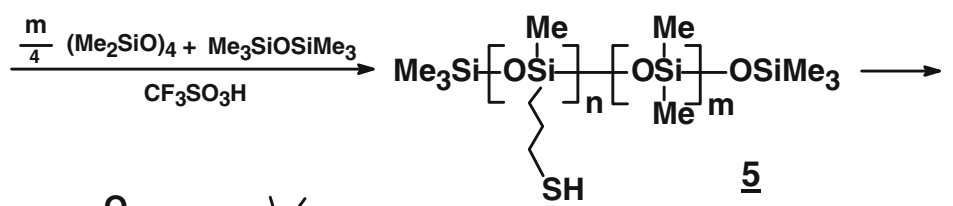

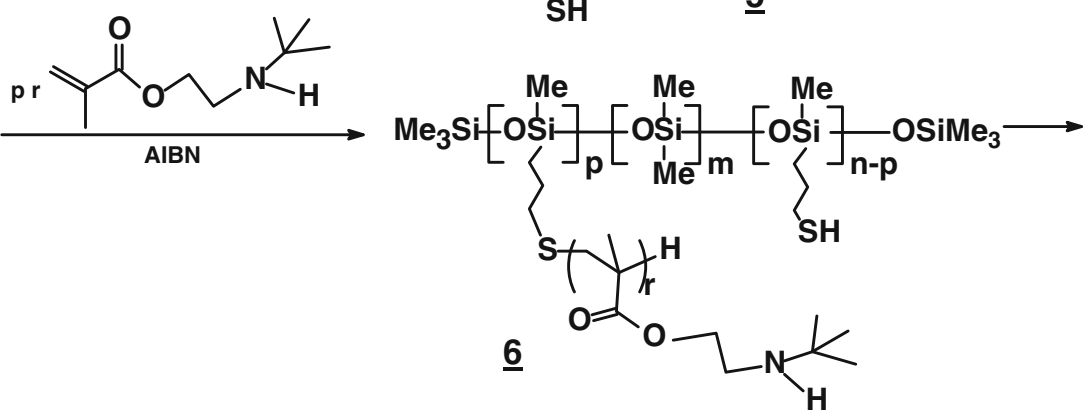

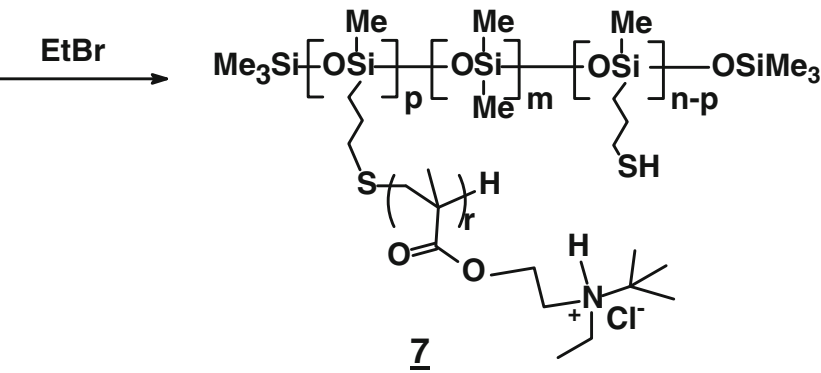

the biocide-bacterial strain pairs the MIC and MBC was evaluated three times with good agreement between these measurements. The results of studies in aqueous solutions are shown in Table 1.

A high antibacterial activity against Gram-positive bacteria was observed for both $t$-butylammonium substituted siloxane copolymers $\mathbf{2 a}, \mathbf{2 b}$ and $\mathbf{7 b}$, although their activity is somewhat lower than that of the polysiloxane substituted by a quaternary ammonium salt with the longer hydrocarbon chain $\mathrm{C}_{8}$ at nitrogen (polymer 8). Copolymers studied here were also active against Escherichia coli but their activity against the other Gram-negative bacteria studied here was very low. This observation seems to be consistent with a mechanism of biocidal action of poly[2( $t$ butylamino)ethyl methacrylate] discussed by Jerome et al. [25]. This mechanism assumes the operation of the charged protonated form of the $t$-butylamino group, thus having a similar structure to the active ammonium groups in our copolymers. The authors assume that these protonated groups are present at the water-polymer interface and exchange their protons to $\mathrm{Ca}^{++}$and $\mathrm{Mg}^{++}$ions, which are 

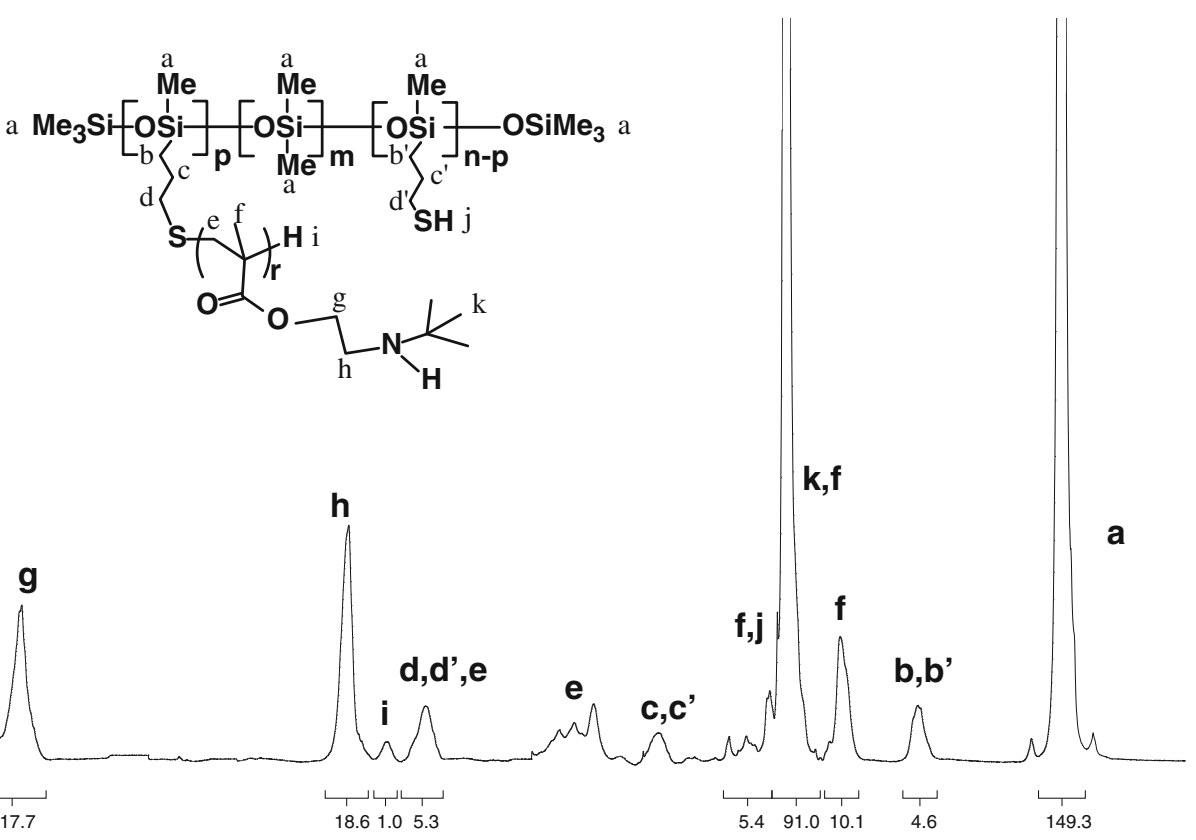

$\begin{array}{llllllllllllllllllllllllll}4.4 & 4.2 & 4.0 & 3.8 & 3.6 & 3.4 & 3.2 & 3.0 & 2.8 & 2.6 & 2.4 & 2.2 & 2.0 & 1.8 & 1.6 & 1.4 & 1.2 & 1.0 & 0.8 & 0.6 & 0.4 & 0.2 & 0.0 & -0.2\end{array}$

Fig. 2 The ${ }^{1} \mathrm{H}$ NMR spectrum of \{poly[(3-mercaptopropyl)methylsiloxane-co-dimethylsiloxane]-graft-poly(2-t-butylaminoethyl methacrylate)\}, copolymer $\mathbf{6 a}$

drawn from the cell membrane of Escherichia coli. This is the cause of the membrane disruption, which leads to the cell death. Gram-positive bacteria have only one membrane, so they are very sensitive to the biocidal action of the $t$-butylamino group in agreement with Jerome's mechanism. On the other hand double membranes cells of Proteus vulgaris and Pseudomonas aeruginosa make the lysis of the cells difficult, although in the case of Escherichia coli the presence of the second membrane does not give the bacteria cell sufficient protection.

In contrast to the data from aqueous solutions, the results of the examination of antibacterial activity of water insoluble polymers (Table 2) can be only compared on a qualitative basis. We believe that the interaction of the polymer with a bacterial cell occurs mostly at the polymerwater interface, although we cannot reject the possibility that a negatively charged bacterial cell in contact with the polymer surface extracts some macromolecules to the aqueous phase. Some of the copolymers studied here were washed eight-times with water after coating the bottom of the multi-dish wells. This operation did not cause a substantial difference in the biocidal activity of these materials as demonstrated in Fig. 3.

However, the results in Table 2 unambiguously point to a high antibacterial activity of our copolymers. Both of them, i.e., one having $t$-butylamine groups pendant to polysiloxane chain and one with the oligo-2-(t-butylamino)ethyl methacrylate grafted on polysiloxane, are very

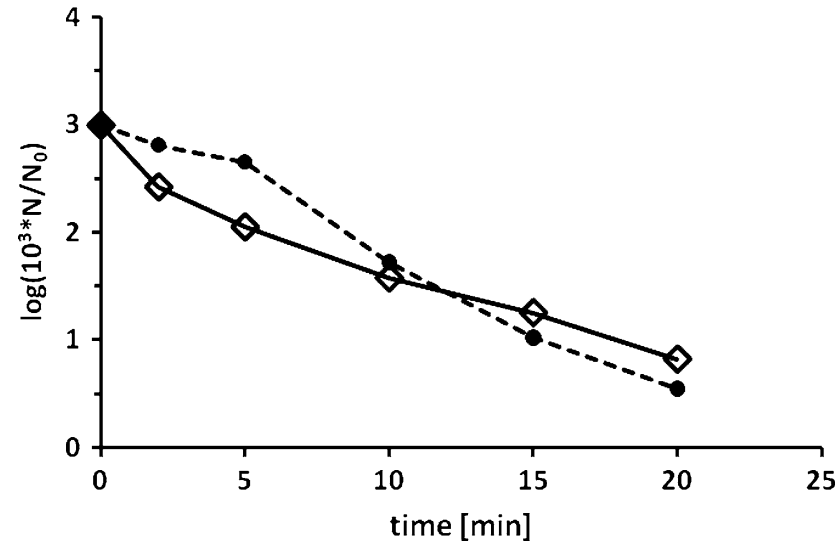

Fig. 3 The reduction of Staphylococcus aureus in its aqueous suspension being in contact with poly-2-t-butylaminoethyl methacrylate grafted on polydimethylsiloxane, copolymer $\mathbf{6 b}$ : solid lines the copolymer used after 8-fold washing with water, dashed lines the copolymer used without the prewashing operation

active against the bacterial strains studied. In particular, they also exhibit a high potency against the Gram-negative strains, which are resistant to their water soluble protonated derivatives. Our preliminary study by SEM showed no bacteria on the biocidal polymer surface after the twophase system experiment; therefore, the reduction of CFU does not seem to be due to the adsorption of bacteria by biocidal surface. The above observations in combination with the results obtained in aqueous solutions may mean that the mechanism of the biocidal action of $t$-butylamino- 
substituted polymers is more complex than it has so far been assumed. In any case, the structure of our copolymers, in particular those of $\mathbf{3 a}$ and $\mathbf{3 b}$, are different from the polymers and copolymers of 2( $t$-butylamino)ethyl methacrylate that were studied in Ref. [25-27]. Therefore, their high antibacterial activity indicates that a high biocidal potency of the $t$-butylamine-substituted methacrylate chain is not only due to a specific structure of the helical polymethacrylate chain, but is rather a general feature of the $t$-butylamino substituent in a polymer chain.

\section{Conclusions}

New siloxane copolymers bearing $t$-butylamine function were synthesized and shown to be active bacteriocides. Polysiloxanes with 3-t-butylaminopropyl groups pendant to polymer chain may be synthesized by the reaction of 3-chloropropylmethylpolysiloxane with $t$-butylamine followed by dehydrochlorination with triethylamine and pyridine. Grafting of poly-2(t-butylamino)ethyl methacrylate on the polysiloxane chain may be performed by free radical polymerization of 2(t-butylamino)ethyl methacrylate in the presence of a polysiloxane substituted with 3mercaptopropyl group that is pendant to the polysiloxane chain. The chain transfer constant to the 3-mercaptopropyl group in this process is $0.6\left(60{ }^{\circ} \mathrm{C}\right)$, thus is fairly close to 1 , which means that the molar ratio of monomer-to-chain transfer groups is little changed as the reaction proceeds. Poly\{[3(t-butylamino)propyl]methylsiloxane-co-(3-chloropropyl)methylsiloxane $\}$ and poly[dimethylsiloxane-co-(3mercaptopropyl)methylsiloxane]-g-poly(2-t-butylaminoethyl methacrylate) show a high antibacterial potency against Gram-positive and Gram-negative bacterial strains when these copolymers are in contact with an aqueous suspension of bacteria. Aqueous solutions of water-soluble derivatives of these polymers, poly\{[3(t-butylamonio) propyl]methylsiloxane chloride-co-3-chloropropylmethylsiloxane and poly[dimethylsiloxane-co-(3-mercaptopropyl) methylsiloxane]-g-poly [2(N,N-t-butylethylammonio)ethyl methacrylate bromide], show a high biocidal activity against Gram-positive bacterial strains (Staphylococcus aureus and Enterococcus hirae). In most cases their MIC and MBC values are in the range of $20-80 \mu \mathrm{g} / \mathrm{mL}$. Their activity against Gram-negative bacteria (Proteus vulgaris and Pseudomonas aeruginosa) is very low; however, they exhibit moderate activity against Escherichia coli (MIC and $\mathrm{MBC}$ are $80-300 \mu \mathrm{g} / \mathrm{mL}$ ).

The biocidal properties of $t$-butyl-substituted polymers are rather general and are related to the presence of $t$-butyl group. The mechanism of the biocidal action of $t$-butylamine substituted polymers is more complex as suggested earlier [25-27]. Antibacterial properties are not only the result of a specific helical conformation of the polymethacrylate chain that bears the amine groups nor are they solely due to a protonated structure of this amine. The biocidal polymers obtained here are uncharged and contain a polysiloxane chain so they should be more compatible with silicone materials as compared with charge-loaded polymers such as cationic polymer biocides.

Acknowledgments The research was supported from the state funds, Project no. N205 129935 and Project no. N205 012834. The supports from The Medical University of Gdansk and from The Center of Molecular and Macromolecular Studies of the Polish Academy of Sciences also are greatly appreciated. The improvement of English of this paper by Prof. Alan Bassindale is also warmly appreciated.

Open Access This article is distributed under the terms of the Creative Commons Attribution Noncommercial License which permits any noncommercial use, distribution, and reproduction in any medium, provided the original author(s) and source are credited.

\section{References}

1. E.R. Kenawy, S.D. Worley, R. Broughton, Biomacromolecules 8, 1359 (2007)

2. S.D. Worley, G. Sun, Trends Polym. Sci. 4, 364 (1996)

3. A.M. Klibanov, J. Mater. Chem. 17, 2479 (2007)

4. T. Tashiro, Macromol. Mater. Eng. 286, 63 (2001)

5. J. Hazziza-Laskar, G. Helary, G. Sauvet, J. Appl. Polym. Sci. 58, $63(1995)$

6. C.Z. Chen, N.C. Beck-Tan, P. Dhurjati, T.K. Van Dyck, R.A. LaRossa, S.L. Cooper, Biomacromolecules 1, 473 (2000)

7. A.D. Fuchs, J.C. Tiller, Angew. Chem. Int. Ed. 45, 6759 (2006)

8. N. Nurdin, G. Helary, G. Sauvet, J. Appl. Polym. Sci. 50, 671 (1993)

9. B. Dizman, M.O. Elasri, L.J. Mathias, J. Polym. Sci. A 44, 5965 (2006)

10. G.Q. Lu, D.C. Wu, R.W. Fu, React. Funct. Polym. 67, 355 (2007)

11. C. Hugues, C. Bessy, P. Bartolomeo, A. Margaillan, Eur. Polym. J. 39, 319 (2003)

12. S. Punyani, H. Singh, J. Appl. Polym. Sci. 102, 1038 (2006)

13. C.Z.S. Chen, S.L. Cooper, Biomaterials 23, 3359 (2002)

14. S. Lenoir, C. Pagnoulle, C. Detrembleur, M. Galleni, R. Jerome, J. Polym. Sci. A 44, 1214 (2006)

15. E.R. Kenawy, F.I. Abdel-Hay, A.E.R.R. El-Shanshoury, M.H. ElNewehy, J. Polym. Sci. A 40, 2384 (2002)

16. A. Kanazawa, T. Ikeda, Coord. Chem. Rev. 198, 117 (2000)

17. A. Kanazawa, T. Ikeda, T. Endo, J. Polym. Sci. A 31, 1467 (1993)

18. G. Cerichelli, C. La Mesa, L. Luchetti, G. Mancini, Langmuir 16, $166(2000)$

19. G.J. Li, J.R. Shen, Y.L. Zhu, J. Appl. Polym. Sci. 78, 668 (2000)

20. J.C. Tiller, S.B. Lee, K. Lewis, A.M. Klibanov, Biotechnol. Bioeng. 79, 465 (2002)

21. U. Mizerska, W. Fortuniak, J. Chojnowski, R. Hałasa, A. Konopacka, W. Werel, Eur. Polym. J. 45, 779 (2009)

22. H. Caner, E. Yilmaz, O. Yilmaz, Carbohydr. Polym. 69, 318 (2007)

23. C. Soykan, R. Coskun, S. Kirbag, J. Macromol. Sci. A 44, 31 (2007) 
24. M. Albert, P. Feiertag, G. Hayn, R. Saf, H. Hönig, Biomacromolecules 4, 1811 (2003)

25. S. Lenoir, C. Pagnoulle, M. Galleni, C. Compere, R. Jerome, C. Detrembleur, Biomacromolecules 7, 2291 (2006)

26. P. Ottersbach, B. Kossmann, German Patent DE 10,244,489 (2004)
27. P. Ottersbach, F. Sosna, Eur. Pat. Appl. EP 1,281,490 (2003)

28. J.M. Andrews, J. Antimicrob. Chemother. 48(Suppl. S1), 87 (2001)

29. G. Sauvet, S. Dupond, K. Kazmierski, J. Chojnowski, J. Appl. Polym. Sci. 75, 1005 (2000)

30. J.C. Saam, D.J. Gordon, J. Polym. Sci. A 8, 2509 (1970) 